\title{
DISPERSAL ACTIVITIES OF THE BLACK-TAILED \\ PRAIRIE DOG OF WIND CAVE NATIONAL \\ PARK, SOUTH DAKOTA
}

\author{
Monte Garrett \\ William L. Franklin \\ Department of Animal Ecology \\ lowa State University \\ Ames, lowa 50011
}

\section{Objectives}

The increase in the size and number of black-tailed prairie dog (Cynomys) ludovicianus) colonies in Wind Cave National Park has been a chronic problem since periodic poisoning programs were discontinued in the mid1960s. In 1967, there were an estimated 254 hectares of prairie dog colonies in the park (Lovaas 1972). Aerial photographs in 1978 indicated an excess of 500 hectares (Dalsted et al. 1981). This worsening condition is alarming to park managers because 1) the native prairie component of the park is shrinking every year due to encroachment of forest and modification by prairie dogs, 2) prairie dogs are believed to be competing for forage with other grazing wildlife (e.g., buffalo and elk), and 3) the park is being accused by local landowners of being a reservoir for prairie dogs infesting adjacent rangeland.

Investigation into the nature of prairie dog dispersal and colony expansion was conducted from 20 May to 20 October 1981, the final year of a 3-year study. The primary objectives were 1) to obtain basic information pertaining to prairie dog dispersal: when movements occur, sex and age of dispersing individuals, distance traveled, and relative success of dispersing individuals; and 2) to test the use of behaviorally based techniques to reduce dispersal and colony expansion.

\section{Methods}

A young expanding prairie dog colony was established as the primary study site in 1979. This colony was monitored for surface expansion and population growth, and as a source of behavioral observations.

Prairie dogs captured away from established colonies were considered dispersing individuals. Data on sex, age, weight, and general physical condition were obtained from all dispersers. As many individuals as time and equipment permitted were fitted with a radiocollar and tracked to their destination. Destination refers to their successful establishment within a colony or to their predation (no disperser initiated a new colony). Behavioral observations of radiocollared prairie dogs at the

$$
-96-
$$


study colony in 1979 found no effect of the collars on the animal's behavior. The radiocollars were designed especially for this study by Cedar Creek Bioelectronics Lab, 2660 Fawn Lake Drive N.E., Bethel, Minnesota.

Because immigrating prairie dogs are usually met with hostility from colony residents (Hoogland 1977, King 1955), all immigrants captured at the study colony also were radiocollared. Prairie dogs immigrating into a colony without being preyed upon, without being driven away by colony residents, and that were still alive when their radiotransmitters failed (approximately 3 months) were considered successful dispersers.

Diethystilbestrol (DES) was administered to prairie dogs at the study colony via hulled oats following Pfeiffer's (1972) specifications. One cup of DES oats was applied to each active burrow mound of the experimental area. Treatment during the 1981 breeding season was the first week of March. At this time there was little growing vegetation available and bait acceptance was good.

\section{Results}

Dispersal was found to be a predictable phenomenon in 1980-81, only occurring during a brief time period in late spring (Figure 1). Observations of prairie dogs away from colonies began in May, reached a peak in early June, and ended by July. Dispersing prairie dogs have never been reported in Wind Cave National Park at other times of the year (Rich Klukas, pers. comm.).

Table 1 summarizes information obtained on dispersing prairie dogs during the 1980-81 dispersal seasons. A total of 34 males and 28 females were found dispersing. Although there was no difference between the sexes in the likelihood of dispersal $\left(X^{2}=.58, P=.75\right)$, males tended to be yearlings while females were of all ages $\left(X^{2}=16.9, P<.005\right)$.

During 1980-81, 16 dispersing prairie dogs were captured, radiocollared, and tracked to their destination (Table 2). Routes followed were those offering the best combination of cover and ease of movement ( $i . e$. , ravines, drainages, weedy roadsides). Therefore, the actual distance traveled was somewhat greater than the straightline distance. Note that these distances were measured from the point of capture; the dispersers were captured en route, and that these figures therefore should be considered the minimum distance. Five prairie dogs (29\%) dispersed across the Wind Cave National Park boundary onto adjacent rangeland.

During the dispersal seasons of $1980-81,29$ prairie dogs were radiocollared. Only 14 of these individuals (48\%) were successful while, during the same time periods, residents of the study colony enjoyed greater than $90 \%$ survival (Table 3$)\left(x^{2}=35.9, P<.005\right)$; Table 4 shows that disperser success did not vary according to sex $\left(x^{2}=.14, P>.50\right)$. Three of the 5 prairie dogs that dispersed out of the park onto adjacent 


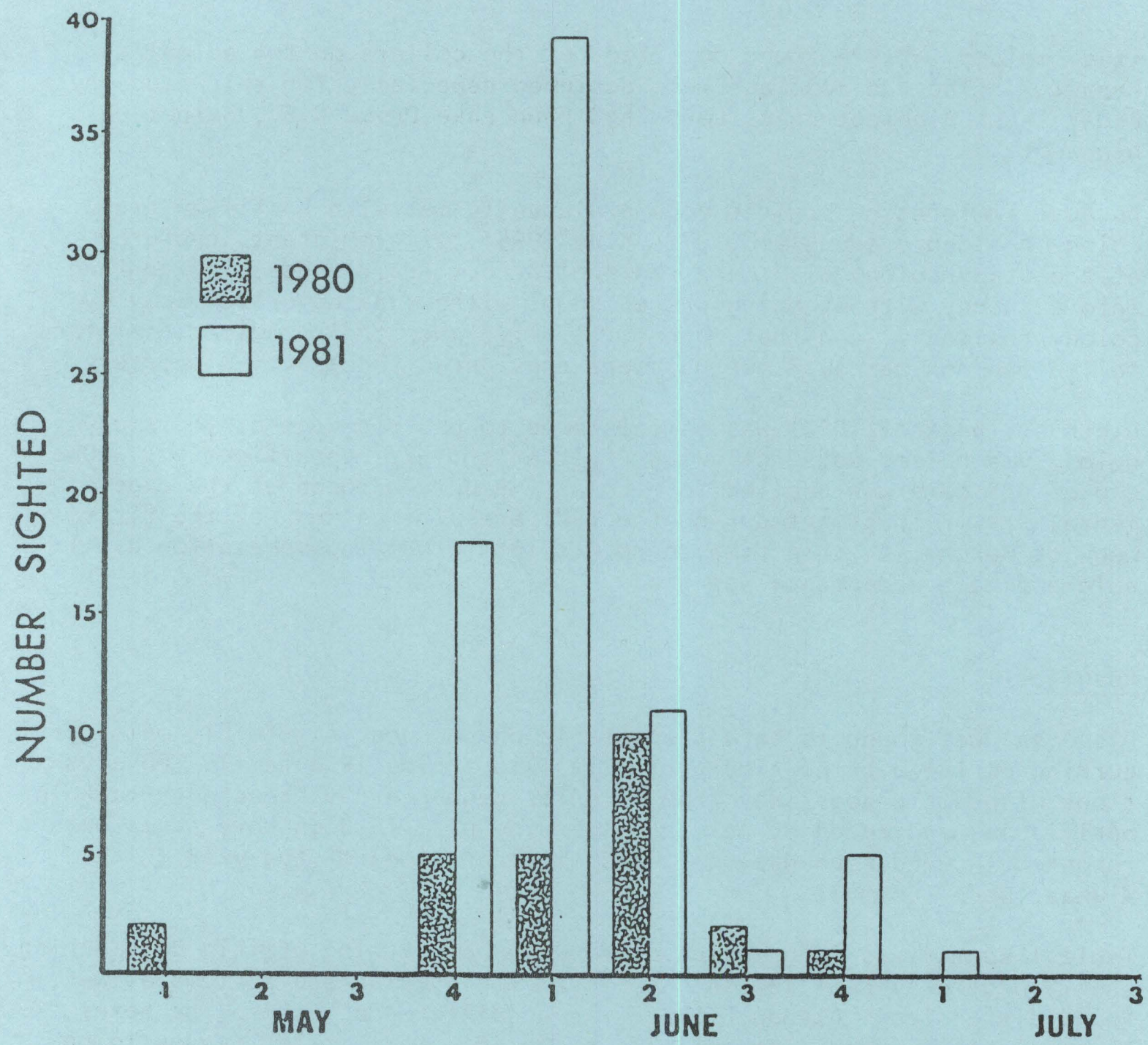

Figure 1. Number of prairie dogs sighted away from prairie dog colonies during the weeks of the dispersal seasons in 1980-81. No prairie dogs were sighted at any other time. 
Table 1. Sex and age of dispersing prairie dogs during 1980-81. Included are live-captured individuals and roadkills found away from prairie dog colonies. Age was determined by comparing relative wear on molars with that of known-age individuals at the study colony.

\begin{tabular}{|c|c|c|c|c|}
\hline \multirow[b]{2}{*}{ Sex } & \multicolumn{3}{|c|}{$A G E$} & \multirow[b]{2}{*}{ Total } \\
\hline & Yearling & 2-Year & $>2-$ Year & \\
\hline Male & 31 & 2 & 1 & 34 \\
\hline \multirow[t]{2}{*}{ Female } & 12 & 8 & 8 & 28 \\
\hline & $\begin{array}{l}\text { Sex }-x^{2}= \\
\text { Age }-x^{2}=1\end{array}$ & $\begin{array}{l}P=.75 \\
P 4.005\end{array}$ & & \\
\hline
\end{tabular}


Table 2. Distance traveled by 16 radiocollared prairie dogs during 1980-81. Included are individuals captured on roadsides away from colonies and immigrants who were captured at, and subsequently dispersed away from, the study colony. Not included are individuals lost during tracking and immigrants that remained at the study colony.

\begin{tabular}{|c|c|c|c|}
\hline Animal & $\begin{array}{l}\text { Date } \\
\text { Captured }\end{array}$ & $\begin{array}{c}\text { Actual } \\
\text { Distance }\end{array}$ & $\begin{array}{c}\text { Straightline } \\
\text { Distance }\end{array}$ \\
\hline 103 & 24 May 1980 & $2.2 \mathrm{~km}$ & $1.9 \mathrm{~km}$ \\
\hline 109 & 6 June 1980 & 0.8 & 0.5 \\
\hline 111 & 10 June 1980 & 2.6 & 1.8 \\
\hline 112 & 10 June 1980 & 6.7 & 5.5 \\
\hline 114 & 12 June 1980 & 2.6 & 1.7 \\
\hline 136 & 27 May 1981 & 4.9 & 4.3 \\
\hline 138 & 31 May 1981 & 6.4 & 4.5 \\
\hline 140 & 31 May 1981 & 3.4 & 2.6 \\
\hline 142 & 31 May 1981 & 1.0 & 0.9 \\
\hline 200 & 3 June 1981 & 4.8 & 3.9 \\
\hline 201 & 4 June 1981 & 3.3 & 2.9 \\
\hline 213 & 7 June 1981 & 0.5 & 0.5 \\
\hline 221 & 11 June 1981 & 1.5 & 1.3 \\
\hline 222 & 15 June 1981 & 5.6 & 4.2 \\
\hline 223 & 20 June 1981 & 0.5 & 0.5 \\
\hline $0^{2} 24$ & 23 June 1981 & 0.8 & 0.7 \\
\hline $\bar{X} \pm S D$ & & $3.0 \pm 2$ & $2.4 \pm 1.7$ \\
\hline
\end{tabular}


Table 3 - Survivorship of radiocollared dispersers compared to residents of the study colony during the dispersal seasons of $1980-81$.

\begin{tabular}{lcc} 
& Died & Survived \\
\hline Dispersers & 15 & 14 \\
Residents & $18^{a}$ & 175 \\
& $\mathrm{X}^{2}=35.9, P<.005$ \\
\hline $\begin{array}{l}\text { B } \\
\text { Because study colony residents were not radiocollared, it was not } \\
\text { dispersed. }\end{array}$
\end{tabular}

Table 4 - Difference in disperser success between $\operatorname{sex}\left(X^{2}=.14, P>.75\right)$ and among different age classes $\left(X^{2}=1.04, P>.50\right)$ during the dispersal seasons of 1980-81.

\begin{tabular}{lcc}
\hline & Successful & Unsuccessful \\
\hline Male & 7 & 8 \\
Female & 7 & 7 \\
$--\ldots$ & 9 & - \\
Yearling & 4 & 9 \\
$2-Y e a r$ & 1 & 3 \\
$>2-Y e a r$ & & 3 \\
\hline
\end{tabular}


rangeland successfully became established in other colonies.

Following Pfeiffer's (1972) specifications, a mixture of hulled oats and DES was administered to 5 coteries (family groups) of the study colony. Five control coteries received the same bait, but without DES. Since individual reproductive histories of the study colony females were known, it was possible to intensively examine the antifertility effects of DES. A comparison of the proportion of females producing litters is presented in Figure 2. Reproduction was similar for the 2 groups in 1979 and 1980, but females receiving DES did not reproduce in 1981 compared with good reproduction in the control coteries. Figure 3 compares colony surface expansion in the 2 areas during the 3 -month period following the emergence of litters. Although the colony had been expanding at a greater rate in 1979 and 1980 in the experimental area, expansion was significantly less in the DES-treated area in 1981 compared with the untreated area $\left(X^{2}=7.64, P<.05\right)$. This probably reflects the low animal density in the treated area (less than half that of the control) due to the lack of young produced in 1981.

\section{Conclusions}

Dispersal of prairie dogs in Wind Cave National Park occurs during, and may be associated with factors particular to, a predictable period of time. May and June are the months of greatest rainfall and thus may assure adequate food and cover for travel. Further, this time period corresponds with juvenile emergence and peak colony densities (King 1955, Koford 1958).

Both male and female prairie dogs disperse. However, the disparity of ages between the sexes suggests that males and females may disperse for different socioecological reasons (Dobson 1978). Our sample of tracked dispersers indicates that movements are relatively short and that mortality of dispersing prairie dogs is high. A healthy population of predators may be instrumental in the natural regulation of these animals. Dispersers may be more successful on private rangeland where frequent poisoning and shooting results in more vacant burrows and a reduced predator population.

The use of DES as a temporary antifertility agent may be a good technique to maintain low animal density and inhibit colony expansion. It is easily applied, well accepted by prairie dogs, and effective. Because prairie dog reproduction occurs only once a year, management efforts would be minimal and would not interfere with other wildlife species.

\section{Literature Cited}

Dalsted, K. J., S. Sather-Blair, B. K. Worcester and R. Klukas. 1981. Application of remote sensing to prairie dog management. J. Range Manage., 34(3): 218-223. 


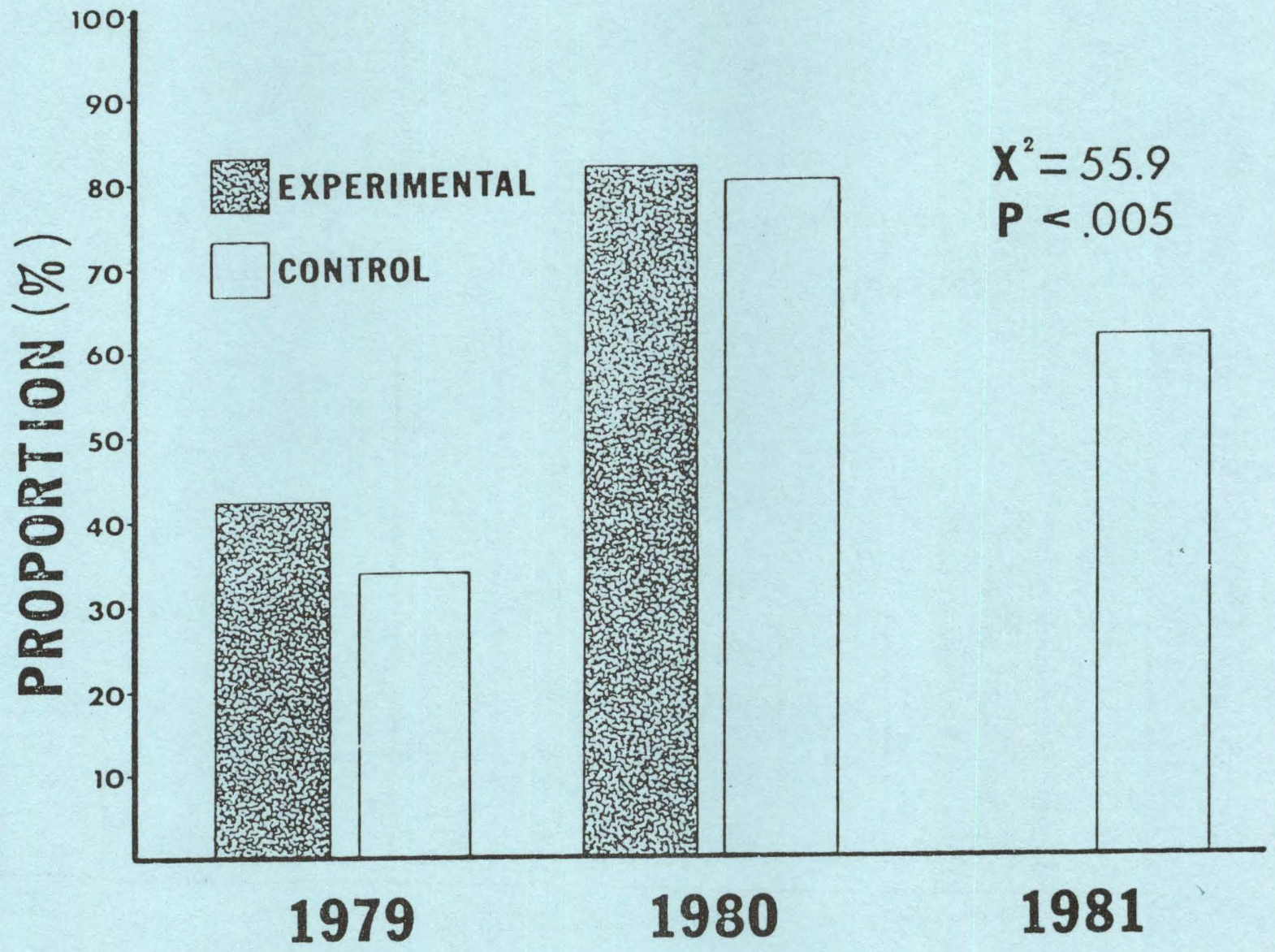

Figure 2. A comparison of the proportion of females producing litters between DES-treated and control coteries (family groups). 


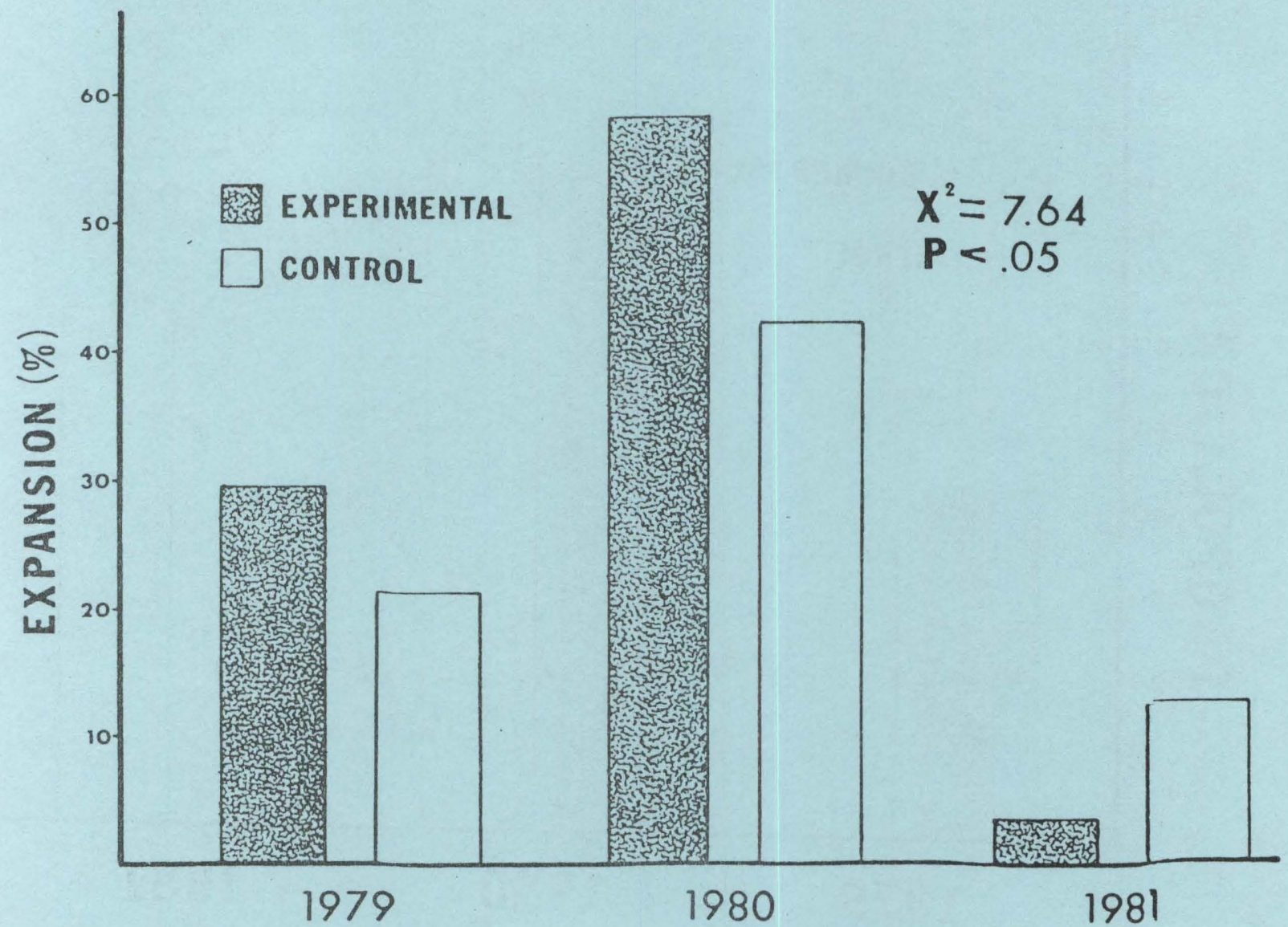

Figure 3. Comparison of percent colony surface expansion between the area treated with DES and the control area. 
Dobson, F. S. 1979. An experimental study of dispersal in the California ground squirrel. Ecology, 60(6): 1103-1109.

Hoogland, J. L. 1977. The evolution of coloniality in white-tailed and black-tailed prairie dogs (Sciuridae: Cynomys leucurus and C. ludovicianus). Ph.D. dissertation, Univ. of Mich., Ann Arbor. 292 pp.

King, J. A. 1955. Social behavior, social organization and population dynamics in a black-tailed prairie dog town in the Black Hills of South Dakota. Contrib. Lab. Vert. Bio. 67., Univ. of Mich. 126 pp.

Koford, C. B. 1958. Prairie dogs, whitefaces, and blue grama. Wildl. Monogr., 3. $78 \mathrm{pp}$.

Lovaas, A. L. 1972. Report on prairie dogs of Wind Cave National Park. WCNP. $19 \mathrm{pp}$.

Pfeiffer, D. G. 1972. Effects of diethylstilbestrol on reproduction in the black-tailed prairie dog. South Dakota State Univ. MS thesis. $45 \mathrm{pp}$.

\section{Acknowledgements}

We thank Les MCClanahan and the entire WCNP staff for their help and cooperation throughout the study. Rich Klukas offered advice and helped in collecting data. Special thanks go to Ahmad Abdunabi, Susie Garrett, Joan Graden, Kurt MacAninch, Terry Johns, and Diane Wright for their assistance in data collection. 